\title{
RESPONSE OF FUNCTIONAL VOMITING WITH CONVENTIONAL
}

\section{ANTIPSYCHOTICS}

\author{
G. Suresh Kumar1, K. V. Rami Reddy², D. Sunitha3, E. Peda Veera Raju
}

\section{HOW TO CITE THIS ARTICLE:}

G. Suresh Kumar, K. V. Rami Reddy, D. Sunitha, E. Peda Veera Raju. "Response of Functional Vomiting with Conventional Antipsychotics". Journal of Evolution of Medical and Dental Sciences 2015; Vol. 4, Issue 07, January 22; Page: 1262-1265, DOI: 10.14260/jemds/2015/174

\begin{abstract}
BACKGROUND: There is a group of patients who have unexplained chronic nausea and/or vomiting. In the past these patients were labeled as having psychogenic vomiting. OBJECTIVE: To assess the response of psychogenic vomiting with conventional antipsychotic chlorpromazine. METHOD: Study was conducted at Department of Psychiatry King George hospital out patients department, Visakhapatnam. $\mathrm{N}=13$ cases with psychogenic vomiting's were treated with Chlorp-romazine of 25-50 mg/ day for two weeks, followed by regular follow up of one month. RESULTS: All the 13 patients who received Chlorpromazine of 25- $50 \mathrm{mg} /$ day for two weeks showed good response. There were no side effects noted with the above dose. CONCLUSIONS: Chlorpromazine of 2 weeks showed good response for patient with psychogenic vomiting.
\end{abstract}

KEYWORDS: Functional vomiting, chlorpromazine.

\section{INTRODUCTION:}

HISTORICAL BACKGROUND: Vomiting of unclear aetiology in $20^{\text {th }}$ century was commonly referred to as psychogenic vomiting. In the past, all chronic unexplained vomiting was typically labeled as 'psychogenic'. Classic papers were published on the topic, notably one in the 1930s and another in the 1960s. These authors assumed their patients had a psychogenic cause because nothing else was found, but no attempt was made to assign a modern psychiatric label or compare their patients with controls.

Psychogenic vomiting is defined by LEIBOVICH ${ }^{1}$ as vomiting without any obvious organic pathology, or 'functional' vomiting, resulting from psychological mechanisms.

Psychogenic vomiting was classified into five patterns of vomiting: continuous, habitual postprandial, irregular vomiting, and self-induced. The common psychiatric disorders related to the onset of vomiting were either a major depression or a conversion disorder. Continuous vomiting was usually due to a conversion disorder, while in many cases of habitual postprandial and irregular vomiting, major depression was observed. The patients' psychiatric disorders and vomiting patterns often changed during the clinical course. Assessing the psychiatric problems and vomiting patterns is important in the diagnosis and treatment of psychogenic vomiting.

HILL $^{2}$ found that many patients had lost a parent in their childhood and felt trapped in a hostile relationship. The aetiology and path physiology of psychogenic vomiting is unclear and guidelines as to its treatment have not yet been established.

Review of Literature: There have been several reports concerning the psychiatric factors involved in the onset of psychogenic vomiting.

Leibovich ${ }^{1}$ has already pointed out the relationship was 'hysterical neurosis, depression and personality disturbances'.' Swanson et $\mathrm{al}^{3}$ reported 77 patients who had nausea as their main 
complaint, although in $73 \%$ of patients it was accompanied by vomiting; 2 in other words, they could be regarded as belonging to the nausea type of psychogenic vomiting.

Concerning treatment, Rosenthal et $\mathrm{al}^{4}$ concluded that most psychogenic vomiting patients could be treated effectively by an empathetic primary care physician. Weddington ${ }^{5}$ and Stravynski ${ }^{6}$ suggested behavioral therapy as treatment.' Haggerty et al and Golden et al7 reported good results using antidepressants. In their study in patients, they used a combination of pharmacotherapy (Minor and major tranquilizers, and anti-depressants) as well as supportive psychotherapy, behavioural therapy and autogenic training.

Oscar H. W. Hill ${ }^{8}$ in his study with chlorpromazine and regular supportive psychotherapy has been followed for 24 months since discharge. During that time his patient was remained at work, despite episodes of vomiting lasting for a few days at a time.

Chlorpromazine has been given for six months after discharge and has remained well, apart from occasional short relapses usually associated with some stress.

OBJECTIVE: To assess the response of psychogenic vomiting with conventional antipsychotic chlorpromazine.

METHODS: Study was conducted at Department of psychiatry King George hospital outpatient department, Visakhapatnam. 13 patients in the study were referred by Department of gastroenterology, king gorge hospital, Visakhapatnam.

All the patients were diagnosed as psychogenic vomiting according to DSM IV TR criteria.

Diagnostic criteria for functional Vomiting: At least 12 weeks in the preceding 12 months of (Does not need to be consecutive)

Frequent episodes of vomiting, occurring on at least 3separte days in a week over 3 months.

Absence of criteria for an eating disorder, rumination, or major psychiatric disease according to DSM IV.

Absence self-induced and medication induced vomiting.

Absence of abnormalities in the gut or central nervous system and metabolic diseases to explain current vomiting.

\section{INCLUSION CRITERIA:}

1. Patients with minimum of two gastroenterologist consultation.

2. Patients with endoscopy and other blood investigations normal.

3. Patients with minimum duration of vomiting since six months and maximum of two years.

Duration of Study: Six Months: All the 13 patients in the study were given chlorpromazine of 25$50 \mathrm{mg} /$ day for duration of two weeks.

Followed by regular follow up of the patients every 2 weeks for duration of one month.

RESULTS: Out of 13 patients, 7 are female patients, and 6 are male patients. 12 out of 13 patients are aged between 15-20 years, and 1 patient is above 25 years.

All the 13 patients showed very good response with very low doses of conventional antipsychotic tab chlorpromazine within two weeks. No side effects were noted with the above doses. 
DISCUSSION: After taking detailed history from the patient and seeing their laboratory investigations, it had been very difficult for the patient to get satisfied response from the treatment received by the gastroenterologist for quite long duration. So all the above samples in the study were referred by the gastroenterologist.

Psychological reasons like depression and conversion disorders were ruled out by applying MINI scale, and were diagnosed as psychogenic vomiting, and were treated.

All the 13 patients who received treatment with tab chlorpromazine of $25-50 \mathrm{mg} /$ day for two weeks showed good response, and were quite satisfied with treatment.

There were no side effects noted with above dosage, and no recurrence of symptoms.

CONCLUSION: Based on this study, our conclusion is that patients with psychogenic vomiting will respond well with chlorpromazine of very low doses over a short period without any side effects and without any recurrence of symptoms.

\section{LIMITATIONS:}

1. No control group.

2. Sample size is very small.

3. Mano metric studies are not done to rule out any motility disorders.

4. Follow-up period might have been longer than the study follow-up.

\section{REFERENCES:}

1. Leibovich MA. Psychogenic vomiting: psychotherapeutic considerations. Psychotherapeutic, Psychosomatic 1973; 22: 263-8.

2. Hill OW. Psychogenic vomiting. Gut 1968; 9: 348-52.

3. Swanson DW, Swenson WM, Huizenga KA, Melson SJ. Persistent nausea without organic cause. Mayo Clin Proc 1976; 51: 257-62.

4. Rosenthal RH, Webb WL, Wruble LD. Diagnosis and Management of persistent psychogenic vomiting. Psychosomatics 1980; 21: 722-30.

5. Weddington WW. Psychogenic nausea and vomiting associated with termination of cancer chemotherapy. Psychother Psychosom 1982; 37: 129-36.

6. Stravynski A. Behavioural treatment of psychogenic vomiting in the context of social phobia. J Nerv Ment Dis 1983; 171: 448-51.

7. Haggerty JJ, Golden RN. Psychogenic vomiting associated with depression. Psychosomatics 1982; 23: 91-5.

8. OSCAR. W. HILL psychogenic vomiting and hypokalaemia. 


\section{REVIEW ARTICLE}

\section{AUTHORS:}

1. G. Suresh Kumar

2. K. V. Rami Reddy

3. D. Sunitha

4. E. Peda Veera Raju

\section{PARTICULARS OF CONTRIBUTORS:}

1. Assistant Professor, Department of Psychiatry, Andhra Medical College, Visakhapatnam.

2. Associate Professor, Department of Psychiatry, Andhra Medical College, Visakhapatnam.

3. Post Graduate, Department of Psychiatry, Andhra Medical College, Visakhapatnam.
4. Emirates Professor, Department of Gastroenterology, Andhra Medical College, Visakhapatnam.

\section{NAME ADDRESS EMAIL ID OF THE CORRESPONDING AUTHOR:}

Dr. G. Suresh Kumar, DPM, DNB Psychiatry, D. No. 50-14-6-3/1,

Seethampeta,

Visakhapatnam, A. P, India.

E-mail: drsuresh27@gmail.com

Date of Submission: 03/01/2015.

Date of Peer Review: 05/01/2015.

Date of Acceptance: 13/01/2015.

Date of Publishing: 21/01/2015. 